\title{
MODELLING OF THE KINETICS OF SULFURE COMPOUNDS IN DESULFURISATION PROCESSES BASED ON INDUSTRY DATA OF PLANT
}

\author{
Nadezhda Krivtcova ${ }^{1, *}$, Anton Tataurshikov ${ }^{1}$, Elena Kotkova $^{1}$ \\ ${ }^{1}$ Tomsk Polytechnic University, Lenin av. 30, Tomsk, 634050, Russia
}

\begin{abstract}
Modelling of sulfur compounds kinetics was performed, including kinetics of benzothiophene and dibenzothiophene homologues. Modelling is based on experimental data obtained from monitoring of industrial hydrotreating set. Obtained results include kinetic parameters of reactions.
\end{abstract}

\section{Introduction}

Desulfurisation - the process of catalytic conversion of hydrocarbons under the influence of substances at high pressure and temperature. Petroleum fractions subjected to desulfurisation to reduce the content of sulfur compounds in gasoline and diesel fuels. Concomitant effect of this process is the saturation of unsaturated hydrocarbons, reduced resin content of oxygenates, and hydrocracking of light hydrocarbon molecules. Desulfurisation - large-refining process and is used in almost all refineries [1].

Due to the increasing role of the hydrotreating processes in the refining industry matures the need to develop software systems that implement mathematical models hydrotreating [2].

The main objective of this study is to model the kinetics of the process of desulfurisation of diesel fuel, with a focus on the dynamics of sulfur-containing compounds (SC), such as sulfides, benzothiophene and dibenzothiophene, the choice of the reactor model.

\section{Object of research}

Typical schematic diagram of a hydrodesulfurization unit is shown in Figure 1. Preheated raw material moves to the hydrotreating reactor $\mathrm{R}$, a major unit of the whole process, where the catalytic hydrotreating of diesel fraction is performed. There are the reactions of sulfur compounds hydrogenation with hydrogen to form hydrogen sulfide performed on the catalyst surface. The hydrogen-containing gas (HCG) is separated from

*Corresponding author: Krivtcovani@mail.ru 
the vapor-liquid mixture in the separators S-1 and S-2 and enters the column C-2 for pure hydrogen to recover. The column $\mathrm{C}-1$ is used for separation of vapor-liquid mixture into gas fraction and the basic product - hydrotreated diesel fuel [3].

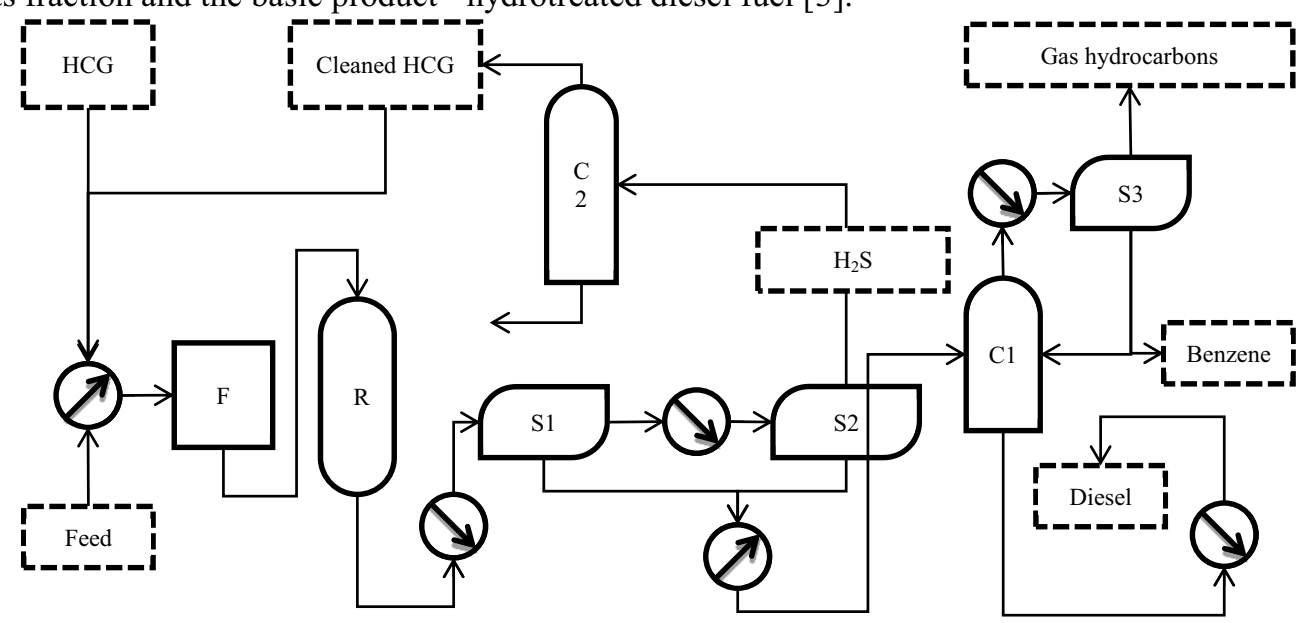

Fig. 1. Typical schematic diagram of hydrodesulfurization unit

The resolution №118 About approval of the Technical regulation about requirements to automobile and aviation gasoline, diesel and ship fuel, jet propulsion fuel and fuel oil dated February 27, 2008 approving technical requirements to the motor fuel was signed by the Russian Federation government. The requirements of GOST R 52368-2005 are brought into compliance with the legal requirements of Euro-3 standard and higher. Prior to that, the fuels were produced in accordance with GOST 305-82. The main difference from the EN 590 standard in the GOST R 52368-2005 is that diesel fuel is divided into three categories depending on the amount of sulfur compounds. Diesel fuel of Type 3 may also be called completely purified.

The plant used French catalyst HR-538, which properties are given in Table 1. The catalyst activity in respect of SC is numerically considered according to the reaction rate constants.

Table 1. HR-538 catalyst properties

\begin{tabular}{|l|c|}
\hline Diameter of catalyst particles, $\mathrm{mm}$ & $1.2 ; 1.6 ; 2.5$ \\
\hline Composition: & 3.5 \\
Nickel (NiO), \% wt. & 17.0 \\
Molybdenum (MoO3), \% wt. & 210 \\
\hline Surface area, $\mathrm{m} 2 / \mathrm{g}$ & \\
\hline
\end{tabular}

\section{Results}

When modeling multicomponent processes can not account each individual component which participates in the chemical process - the number of components 300-400 in the case of the desulfurisation [4]. But, at the same time, the mathematical model must be sensitive to the changing composition of the raw material. Only in this case, the model will be adequate to the real process and will have predictive ability $[2,4]$.

The change of Gibbs free energy provided by the reactions calculated using software packages HyperChem and Gaussian 09 [5]. In previous work, studies were conducted to determine the kinetic parameters of the hydrodesulfurization reactions $[6,7,8]$ (Table 2). 
Table 2. Changing the Gibbs energy of reaction hydrogenation SC

\begin{tabular}{|c|c|c|}
\hline № & $\Delta \mathrm{G}, \mathrm{kJ} / \mathrm{mol}$ & Reaction \\
\hline 1 & $-95,3$ & $C_{9} H_{9} S+3 H_{2} \rightarrow C_{9} H_{13}+H_{2} S$ \\
\hline 2 & $-83,5$ & $C_{10} H_{11} S+3 H_{2} \rightarrow C_{10} H_{15}+H_{2} S$ \\
\hline 3 & $-71,1$ & $C_{11} H_{13} S+3 H_{2} \rightarrow C_{11} H_{17}+H_{2} S$ \\
\hline 4 & $-65,1$ & $C_{12} H_{8} S+2 H_{2} \rightarrow C_{12} H_{10}+H_{2} S$ \\
\hline 5 & $-54,3$ & $C_{13} H_{11} S+2 H_{2} \rightarrow C_{13} H_{13}+H_{2} S$ \\
\hline 6 & $-53,7$ & $C_{14} H_{13} S+2 H_{2} \rightarrow C_{14} H_{15}+H_{2} S$ \\
\hline 7 & $-49,4$ & $C_{15} H_{15} S+2 H_{2} \rightarrow C_{15} H_{17}+H_{2} S$ \\
\hline
\end{tabular}

On the basis of calculations of thermodynamic parameters of the reactions taking place in the process of desulfurization of diesel fuel is made up of substances mathematical model. The developed mathematical model based on the law of mass action and is a system of differential equations, which reflect changes in the concentrations of the reactants:

benzothiophene

$$
\begin{gathered}
\left\{\begin{array}{l}
W_{1}=k_{C_{1} B \mathrm{~T}} C_{C_{1} B \mathrm{~T}} C_{H_{2}}^{v} \\
W_{2}=k_{C_{2} B \mathrm{~T}} C_{C_{2} B \mathrm{~T}} C_{H_{2}}^{v} \\
W_{3}=k_{C_{3} B \mathrm{~T}} C_{C_{3} B \mathrm{~T}} C_{H_{2}}^{v}
\end{array}\right. \\
\left\{\begin{array}{l}
\frac{d C_{C_{1} B \mathrm{~T}}}{d t}=W_{1} \\
\frac{d C_{C_{2} B \mathrm{~T}}}{d t}=W_{2} \\
\frac{d C_{C_{3} B T}}{d t}=W_{3}
\end{array}\right.
\end{gathered}
$$

dibenzothiophene

$$
\begin{gathered}
\left\{\begin{array}{l}
W_{4}=k_{D B \mathrm{~T}} C_{D B T} C_{H_{2}}^{v} \\
W_{5}=k_{C_{1} D B \mathrm{~T}} C_{C_{1} D B \mathrm{~T}} C_{H_{2}}^{v} \\
W_{6}=k_{C_{2} D B \mathrm{~T}} C_{C_{2} D B \mathrm{~T}} C_{H_{2}}^{v} \\
W_{7}=k_{C_{3} D B \mathrm{~T}} C_{C_{3} D B \mathrm{~T}} C_{H_{2}}^{v}
\end{array}\right. \\
\left\{\begin{array}{l}
\frac{d C_{D B T}}{d t}=W_{4} \\
\frac{d C_{C_{1} D B T}}{d t}=W_{5} \\
\frac{d C_{C_{2} D B T}}{d t}=W_{6} \\
\frac{d C_{C_{3} D B T}}{d t}=W_{7}
\end{array}\right.
\end{gathered}
$$

Initial conditions: $d C_{i}=C_{i, 0} ; t=0$

where $k_{i}$ - rate constant of the component $i ; C_{i}$ - the current concentration of the substance $i ; v$ - the stoichiometric ratio.

To study the data taken from the monitoring installation LG-24/7, reflecting the state of technological parameters are shown in Table 3.

Table 3. Technological parameters of plant LG-24/7

\begin{tabular}{|l|c|c|c|}
\hline Day & 23.12 .14 & 24.12 .14 & 25.12 .14 \\
\hline Rate, $\mathrm{m}^{3} / \mathrm{h}$ & 80,15 & 79,97 & 80,24 \\
\hline Volume rate of feed $\mathrm{m}^{3} / \mathrm{m}^{3}$ & 1,336 & 1,333 & 1,337 \\
\hline Temperature, ${ }^{\circ} \mathrm{C}$ & 333,12 & 333,30 & 333,12 \\
\hline Presure, $\mathrm{kgf} / \mathrm{sm}^{2}$ & 33,709 & 33,774 & 33,734 \\
\hline
\end{tabular}




\begin{tabular}{|l|l|l|l|}
\hline Raw sulfur content, \% mas. & 0,8200 & 0,9000 & 0,8800 \\
\hline Product sulfur content, \% mas. & 0,0030 & 0,0040 & 0,0030 \\
\hline The length of the reaction zone, m & \multicolumn{3}{|c|}{8} \\
\hline Volume of catalyst, $\mathrm{m}^{3}$ & \multicolumn{2}{|c|}{26} \\
\hline
\end{tabular}

As the basis of hydrodynamic models taken quasi-homogeneous stationary model of a plug flow reactor according to equation:

$$
\frac{d C_{r}}{d l}=-U * \sum_{i=1}^{p} W_{i}
$$

where $l$ - the length of the reactor; $U$ - the linear velocity of feed; $p$ - quantity of reagents and products by route $r ; W_{i}$ - the rate of the chemical reaction.

Calculated data obtained as a result of the mathematical model are shown in Table 4. The pressure in the reactor vapor-liquid mixture is from 30 to $34 \mathrm{kgf} / \mathrm{cm} 2$. The temperature in the reactor for the entire installation work cycle was in the range from 320 to $350^{\circ} \mathrm{C}$.

Table 4. The calculated rate constant transformation of components $\mathrm{h}^{-1}$

\begin{tabular}{|l|c|c|c|}
\hline \multicolumn{1}{|c|}{ Day } & 23.02 .15 & 24.02 .15 & 25.02 .15 \\
\hline $\mathrm{C}_{9} \mathrm{H}_{9} \mathrm{~S}+3 \mathrm{H}_{2} \rightarrow \mathrm{C}_{9} \mathrm{H}_{13}+\mathrm{H}_{2} \mathrm{~S}$ & 1,58 & 1,51 & 1,60 \\
\hline $\mathrm{C}_{10} \mathrm{H}_{11} \mathrm{~S}+3 \mathrm{H}_{2} \rightarrow \mathrm{C}_{10} \mathrm{H}_{15}+\mathrm{H}_{2} \mathrm{~S}$ & 1,51 & 1,45 & 1,54 \\
\hline $\mathrm{C}_{11} \mathrm{H}_{13} \mathrm{~S}+3 \mathrm{H}_{2} \rightarrow \mathrm{C}_{11} \mathrm{H}_{17}+\mathrm{H}_{2} \mathrm{~S}$ & 1,51 & 1,44 & 1,53 \\
\hline $\mathrm{C}_{12} \mathrm{H}_{8} \mathrm{~S}+2 \mathrm{H}_{2} \rightarrow \mathrm{C}_{12} \mathrm{H}_{10}+\mathrm{H}_{2} \mathrm{~S}$ & 1,35 & 1,30 & 1,37 \\
\hline $\mathrm{C}_{13} \mathrm{H}_{11} \mathrm{~S}+2 \mathrm{H}_{2} \rightarrow \mathrm{C}_{13} \mathrm{H}_{13}+\mathrm{H}_{2} \mathrm{~S}$ & 1,37 & 1,32 & 1,39 \\
\hline $\mathrm{C}_{14} \mathrm{H}_{13} \mathrm{~S}+2 \mathrm{H}_{2} \rightarrow \mathrm{C}_{14} \mathrm{H}_{15}+\mathrm{H}_{2} \mathrm{~S}$ & 1,27 & 1,22 & 1,29 \\
\hline $\mathrm{C}_{15} \mathrm{H}_{15} \mathrm{~S}+2 \mathrm{H}_{2} \rightarrow \mathrm{C}_{15} \mathrm{H}_{17}+\mathrm{H}_{2} \mathrm{~S}$ & 0,70 & 0,67 & 0,71 \\
\hline Calculated product sulphur content, \% mass. & 0,0031 & 0,0042 & 0,0030 \\
\hline Experimental product sulfur content, \% mas. & 0,0030 & 0,0040 & 0,0030 \\
\hline Relative sulphur calculation error, \% & 3,333 & 5,000 & 0,000 \\
\hline
\end{tabular}

\section{Conclusion}

The result of the study is successful in building a mathematical model, including the analysis of experimental data, the aggregation kinetic scheme, the development of mathematical models and software, performing calculations.

The relative error of calculation that was conducted on the data for the entire installation of the monitoring period, amounted to no more than $5 \%$ on the total sulfur content in the product desulfurisation. It confirmed a direct correlation conversion rate constant calculated from the sulfur-containing component of the Gibbs energy of the hydrogenolysis reaction.

According to the latest Euro-5 standards governing the quality of diesel fuel, the maximum sulfur content in it should not exceed $10 \mathrm{ppm}$. According to the results of 
calculations a residual sulfur content exceeds the threshold of $10 \mathrm{ppm}$ even at $356{ }^{\circ} \mathrm{C}$ and raw material consumption from 50 to $60 \mathrm{~m}^{3} / \mathrm{h}$.

\section{References}

1. Anne Belinda Bjerre, Emil Sorensen. Ind. Eng. Chem. Res. 1992, V. 5, 31, 15771580 .

2. Ed Palmer, Stan Polcar and Anne Wong, PTQ, 2009. 91-100.

3. Emiel J.M. Hensen. Hydrodesulphurization catalysis and mechanism of supported transition metal sulfides. Eindhoven: Technische Universiteit Eindhoven. 2000. 254 p.

4. Krivtsova N. I., Ivanchina E. D., Tataurshchikov A. A. XXI International Conference on Chemical Reactors (CHEMREACTOR 21). Delft, September 22-25, 2014. 392393.

5. Belinskaya N.S., Ivanchina E.D., Ivashkina E.N., Silko G.Yu., Frantsyna E.V. Izvestiya vuzov: Chemistry and Chemical Technology, 2014. V. 57. №. 11, 90-92.

6. N.I. Krivtcova, A.A. Tataurshikov, I.D. Ivanchina, E.B. Krivtsov, A.K. Golovko. Procedia Engineering / Volume 113, 2015. 73-78

7. Tataurshikov A., Ivanchina E., Krivtcova N., Krivtsov E., Syskina A. IOP Conference Series: Earth and Environmental Science. Volume 27, Issue 1, 10 November 2015.

8. Krivtcova N.I., Tataurshikov A.A., Ivanchina I.D., Krivtsov E.B., Golovko A.K. Procedia Engineering. Volume 113, 2015, Pages 73-78. 